\title{
ABOUT USING THE GEOPHYSICAL STUDY METHODS TO PREVENT DRILLING PROBLEMS
}

• . ршуков , . ерябин

L. A. Parshukova, A. V. Deryabin

юменский индустри льный университет, г. юмень

лючевые слов : устойчивость ствол скв жины; осложнения при бурении неустойчивых горных пород; комплекс позволяющий прогнозиров ть проблемные интерв лы с точки зрения устойчивости

Key words: well borehole stability, problems of drilling incompetent rocks; borehole survey complex to predict the problem intervals in terms of stability 
геологическом р зрезе ургутского р йон имеются интерв лы неустойчивых глин. урение д нных интерв лов сопряжено с риском возникновения р зличного род осложнений (потери циркуляции, мех нического прихв т колонны и пр.), но н иболее ч сто встреч ются осложнения при проведении подъем компоновки низ бурильной колонны ( ) и при спуске обс дных колонн. ти осложнения проявляются в виде з тяжек бурильного инструмент вплоть до потери подвижности колонны и в виде p згрузок вес при спуске обс дных колонн с высокой вероятностью недохождения обс дной колонны до проектной глубины. ледов тельно, д нные осложнения несут большие экономические потери буровому предприятию.

результ те проведенного н лиз ди гр мм бурения, количеств и х р ктер выбуренной породы н первой ступени очистки, информ ции по результ т м геофизических исследов ний, исследов ний кернового м тери л были определены вертик льные отметки интерв лов, н иболее оп сных с точки зрения потери устойчивости ствол скв жины. ти интерв лы предст влены в тской $(1160-1430$ м), нтынсийской (1 430-1 720 м.) и икуловской (1 720-2 030 м) свит ми. нные интерв лы предст влены бсолютно р зными по сост ву и свойств м горными пород ми. пример, в тск я свит содержит мелко- и среднезернистый песч ник субконтинент льного генезис, нты- нсийск я свит сложен глин ми, пересл ив нием глин и песч ников, икуловск я свит сложен преимущественно сл босцементиров нными песч ник ми и левролит ми. осле обобщенного н лиз полученной информ ции был сдел н вывод о том, что первопричин осложнений н месторождениях ургутского р йон - потеря устойчивости ствол скв жин.

ричины н рушения устойчивости ствол скв жины р знообр зны. сновными являются изменение н пряженно-деформиров нного состояния горных пород после пробурив ния скв жины в горном м ссиве, т кже вз имодействие глинистых пород, сл г ющих д нный геологический р зрез, с водной ф зой буровых р створов. ледов тельно, для предупреждения н рушения устойчивости ствол скв жины применяют дв основных н пр вления: для ур вновешив ния н пряженного состояния н стенк х ствол скв жины применяют буровые р створы повышенной плотности, с целью предупреждения вз имодействия глин и водной ф зы применяют р зличные химре генты-ингибиторы и р зличные методы кольм т ции [1-4].

льтерн тивным методом предупреждения осложнений при бурении является $\mathrm{p}$ 3p ботк безоп сных (с точки зрения устойчивости) профилей стволов скв жин. ля определения оп сных зон . . оргоцем [5] предл г ется использов ть сейсмические исследов ния. роведение сейсмических исследов ний н месторождении позволило выявить неоднородность волнового поля, что было интерпретиров но к к тектоническое н рушение. олновые ном лии, определенные по результ т м обр ботки всех д нных, были объединены и н несены н структурную к рту. кже н к рту были н несены профили скв жин. ыло отмечено, что именно в мест х, где профили скв жин пересек ют линии предпол г емых тектонических р зломов, н блюд ются н иболее интенсивные осложнения при бурении (сильные обв лы стенок, з тяжки и пос дки при проведении спуско-подъемных опер ций).

тмеч ется, что при определении уч стков скв жин, поп д ющих в т кую ном лию, необходимо учитыв ть т кже ширину (обл сть) ее действия. связи с тем, что были использов ны 2D сейсмические д нные, не предст вляется возможным точно определить зону (гр ницу) простир ния н рушения между выявленными ном лиями.

целью увеличения точности определения зон тектонических н пряжений н иболее верно иметь декв тную модель тектонических н рушений. ложность построения декв тной модели з ключ ется в следующих момент х. о-первых, необходимо учитыв ть иер рхично-блочную структуру м ссивов горных пород, где выделяют поля тектонических н пряжений р зличного уровня (р змер ): глоб льные > регион льные $>$ лок льные > ч стные. к ждом уровне (p змере) блок выделяют свои индивидульные определяющие ф кторы, приводящие к изменению н пряженных состояний в горном м ссиве [7]. о-вторых, необходимо учитыв ть действие временного ф ктор н состояние м ссивов пород - в результ те рел кс ции н пряжений з длительный 
период времени существов ния м ссив имеющееся поле н пряжений имеет тенденцию к выр внив нию, то есть поля н пряжений тр нсформируются в р внокомпонентные.

ля построения м тем тической модели н пряженных состояний горного м ссив и для решения любых з д ч геомех ники необходимо иметь декв тную, постоянно обновляемую геологическую модель м ксим льно возможного геоблок . ля решения д нной з д чи эффективно использов ть в комплексе сейсмические и кустические методы исследов ний.

ля определения м ксим льного сжим ющего н пряжения эффективно использов ть комплекс методов: профилеметрию, (скв жинный кустический телевизор),

(пл стовый н клономер), к вернометрию. нный комплекс приборов позволяет определить н личие, н пр вление, р змер трещин и желобов в скв жине, т кже поперечные р змеры и конфигур цию стенок ствол скв жины. л год ря н личию информ ции о н пр влении и р змер х трещин можно определить н пр вление м ксим льного сжим ющего н пряжения, т к к к известно, что обр зующиеся трещины ориентиров ны вдоль миним льного сжим ющего н пряжения, миним льное н пряжение перпендикулярно м ксим льному сжим ющему н пряжению.

результ те н лиз д нных профилеметрии скв жин было отмечено, что в н пр влении одной из осей поперечного сечения стволов отмеч ется уменьшение ди метр скв жины, в н пр влении другой оси - увеличение ди метр (рис. 1), что свидетельствует о н личии н пряжений в горном м ссиве, т кже о вз имосвязи н пр влений эллипсовидных р сширений ствол скв жины с горизонт льным н пряжением пород. ст новлено, что н пр вление р сширения ствол скв жины перпендикулярно н пр влению вектор н пряжений пород.

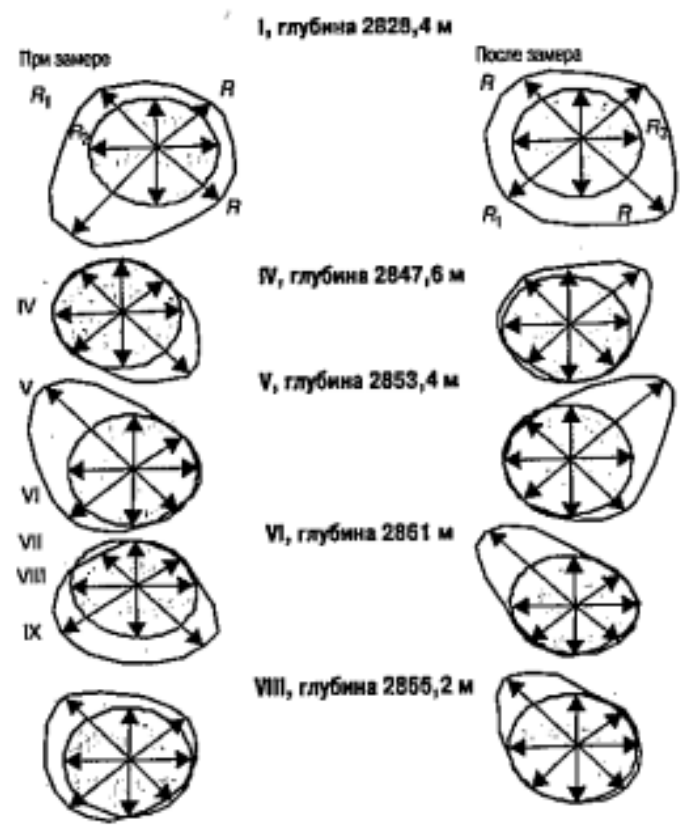

ис. 1. рофилеметрия ствол скв жины спользов ние профилеметрии [6] позволило четко выделить интерв лы р сположения зон обв лов пород в скв жине. ля того чтобы проследить дин мику процесс обв лообр зов ния, необходимо периодически определять поперечные р змеры и конфигур цию стенок скв жины.

н стоящее время в нефтяной промышленности двумя основными метод ми определения прочности пород являются л бор торные исследов ния н одноосное и трехосное сж тие согл сно 21153.2-84 либо проведение кустического к рот ж в открытом стволе скв жины. огл сно $\mathrm{p}$ бот м [7], к рот жные д нные совп д ют с л бор торными исследов ниями для р зных типов пород и являются первоисточником при д льнейшем проектиров нии скв жин. роведение л бор торных испыт ний огр ничено количест-

вом отобр нных обр зцов керн, к рот жные исследов ния позволяют получить информ цию для принятия опер тивных решений и р зр ботки мероприятий с целью обеспечения устойчивости ствол скв жин по всему открытому стволу.

дной из х р ктеристик, полученных с помощью широкополостного кустического к рот ж и д ющих четкое предст вление о м ксим льно возможных н грузк х н породу, является метод UCS - Unconfined compressive strength (предел прочности н одноосное сж тие ( )), который предст вляет собой м ксим льное зн чение осевого сжим ющего н пряжения, которое может выдерж ть пород . редел прочности н 
одноосное и трехосное сж тие выр ж ется в п ск лях ( ) и может быть р ссчит н по полученным д нным в результ те проведения кустического к рот ж .

рис. 2 предст влен пример результ тов кустического к рот ж, совмещенного со схем тической литологической колонкой и д нными к вернометрии, 3 пис нным н глубине 2 100-2 450 м по вертик ли [8]. сследуемый р зрез предст влен доломит ми и сл нц ми (нижняя ч сть рисунк ): сл нцевые отложения н ди гр мме отобр жены темным фоном; отложения доломитов отобр жены светлым фоном. средней ч сти рисунк отобр жен ди гр мм р ссчит нной . верхней ч сти гр фик предст влен к верногр мм.

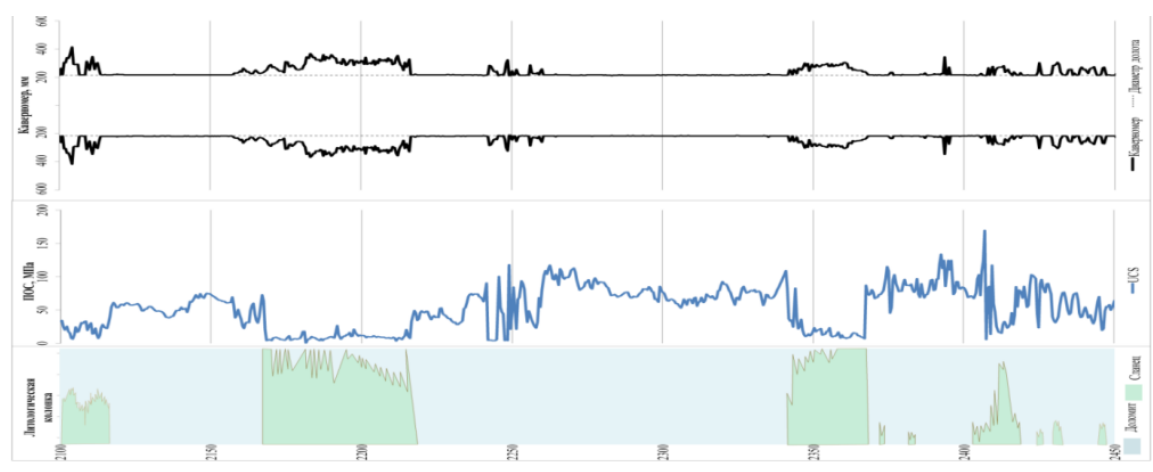

ис. 2. спределение воткрытом стволе поднным . . ужников

рис. 2 отчетливо видн з висимость увеличения ди метр ствол скв жины (увеличение к вернозности) и уменьшение зн чений именно в интерв л х з лег ния неустойчивых сл нцев. о д нному рисунку можно з ключить, что применение метод широкополосного кустического к рот ж в комплексе с к верномером позволяет дост точно точно определить интерв лы ствол с изменением зн чений предел прочности н одноосное сж тие. ким обр зом, можно выявить интерв лы з лег ния и мощность неустойчивых глинистых пропл стков.

ри проведении широкополосного кустического к рот ж прибор ми или

получ ют д нные о скоростях р спростр нения упругих продольных и поперечных волн. н я эти скорости, применяя м тем тические формулы, определяются упругие дин мические х р ктеристики основных пород (коэффициент у ссон, модуль сдвиг, модуль нг ).

1. пределение коэффициент у ссон $v$ :

$$
v=\frac{0,5-R^{2}}{1-R^{2}},
$$

где $\mathrm{R}$ - отношение скорости поперечной волны $v_{s}$ к скорости продольной волны $v_{p}$.

2. пределение модуля упругости :

$$
=\frac{\delta v_{s}^{2}\left(3 v_{p}^{2}-4 v_{s}^{2}\right)}{v_{p}^{2}-v_{s}^{2}},
$$

где $\sigma$ - плотность породы; $v_{s}-$ скорости поперечной волны; $v_{p}-$ скорость продольной волны.

3. пределение модуля сдвиг для плоскости изотропии $G$ :

$$
G=\frac{E}{2(1+v)},
$$

где $G$ - модуль сдвиг плоскости; - модуль нг ; $v$ - коэффициент у ссон .

4. пределение миним льного горизонт льного (р ди льного) н пряжения:

$$
\delta \min =\frac{\mu}{1-\mu}\left(\mathrm{p}_{\mathrm{ovb}}-\gamma \mathrm{p}_{\mathrm{p}}\right)
$$


где - модуль у ссон ; $P_{o v b}$ - горное д вление; $P_{p}$ - поровое д вление; $\gamma$ - коэффициент иот .

рименение сейсмического лок тор бокового обзор ( $\quad$ ) позволяет получить ценную информ цию для построения кту льной геологической модели. етод применяется для изучения простр нственного (3D) и простр нственно-временного (4D) поля открытой трещинов тости в геосреде. к было ск 3 но выше, лок ция, p змер и н пр вление трещин позволяют определить н пр вление векторов н пряжений в горном м ссиве, т кже н личие зон

нформ ция о доминирующих н пр влениях открытой трещинов тости, полученн я по д нным , может быть использов н для 3 д ния оптим льных зимут льных н пр влений бурения горизонт льных и н клонных стволов скв жин [9] (рис. 3).

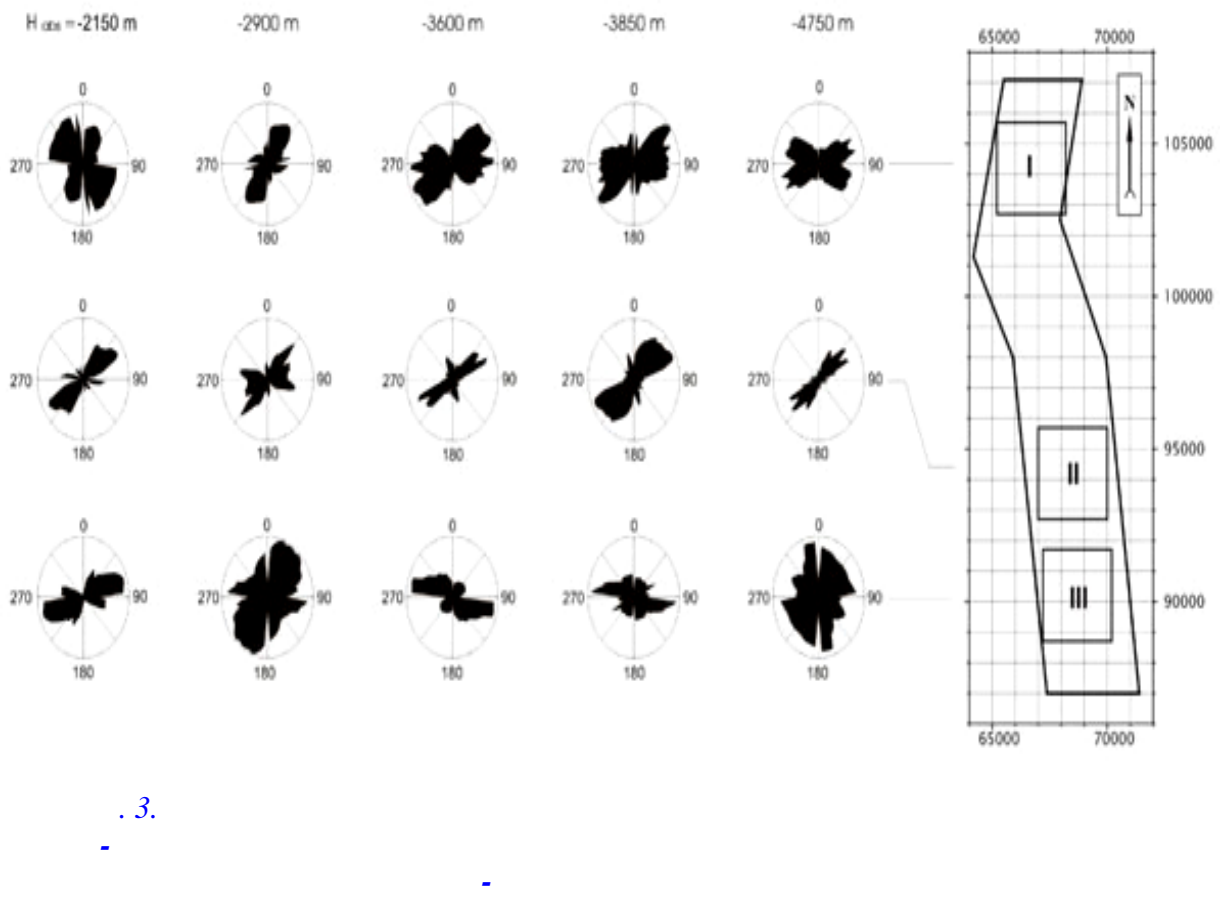

езюмируя вышеск з нное, использов ние геофизических методов исследов ний в комплексе позволит построить геологическую модель месторождения, поддержив ть ее в кту льном состоянии, выявлять оч говые зоны скопления пл стовых флюидов, определять оп сные зоны для бурения и н проектном уровне р зр б тыв ть мероприятия, н пр вленные н без в рийную проводку стволов скв жин.

писок литер туры

1. с чев с. рошев _. рисяжнюк_. сновные спекты оценки устойчивости ствол скв жины н примере огожниковского месторождения // урение скв жин. - 2009- С. 79-87.

2. ддолотные кольм т торы и кольм т торы-к либр торы. стройство кольм тирующее [ лектронный pecypc]. - ежим доступ : http://www.neftepromcentr.ru/ustrojstvo_kol'matirujuwee_uok.htm.

3. тников . ., ом нов . ., оздря . . ольм тирующие н полнители широкого спектр действия производств « « олицелл» // урение и нефть. - 2012. - № 10. - .32-35.

4. неев . ., ильм нов . ., хтияров . . некоторых н пр влениях повышения эффективности бурения в неустойчивых пород х // ефтепромысловое дело. - 2015. - № 10. - . 43-45.

5. оргоц . ., б ров . ., ороль . . н лиз влияния тектонических н пряжений н устойчивость стенок ствол скв жины // опросы геологии, бурения и $\mathrm{p}$ зр ботки нефтяных и г зонефтяных месторождений ургутского р йон : сборник н учных трудов. - .: зд-во « ефтяное хозяйство», 2012. - .38-43.

6. оргоц . ., ихонов . ., уприянов . . роблемы определения вектор тектонических н пряжений в стенке ствол скв жины // опросы геологии, бурения и р зр ботки нефтяных и г зонефтяных месторождений ургутского р йон : сборник н учных трудов. - $\quad . \quad$ зд-во « ефтяное хозяйство», 2012. - .44-51.

7. нв р ., р ун . оделиров ние мех нических свойств геологической среды к к средство р сшифровки н пряжений в горных пород х // ефтег зовое обозрение. - 2005.- .9. - № 1. - . 20.

8. ужников . . лияние прочностных свойств литифициров нных отложений н ст бильность ствол скв жины // ефтег зовое дело. - 2014. - № 1. - . 1-9. 
9. ейсмический лок тор бокового обзор « сероссийский н учно-исследов тельский институт геологических, геохимических и геофизических систем» [ лектронный ресурc]. - ежим доступ : http://www.geosys.ru/index. $\mathrm{php} / \mathrm{ru} / \mathrm{slbo.html}$

н полезную модель № 145681 « ромывочный к либр тор».

\section{ведения об втор $x$}

риуков юдмил

лекс ндровн

к. т. н., доиент к федры « урение нефтяных и

2 зовых скв жин», юменский индустри льный университет, г. юмень, тел. 8 (904)980622

ерябин ндрей л димирович, спир нт $\kappa$ федры « урение нефтяных $и$ г зовых скв жин», юменский индустри льный университет, 2. юмень, тел. 8(3452)390363

\section{Information about the authors}

Parshukova L. A., Candidate of Science in Engineering, associate professor of the chair $«$ Drilling of oil and gas wells», Industrial University of Tyumen, phone: 8 (904)980622

Deryabin A. V., drilling engineer, OJSC «Surgutneftegas", postgraduate of the chair "Drilling of oil and gas wells», Industrial University of Tyumen, phone: 8(3452)390363 